\title{
A Structural Calculation Model of Shield Tunnel Segment: Heterogeneous Equivalent Beam Model
}

\author{
Mingfeng Lei $\mathbb{D}^{1,2}$ Dayong Lin, ${ }^{1}$ Chenghua Shi, ${ }^{1}$ Jianjun $M a\left(\mathbb{D},{ }^{3}\right.$ and Weichao Yang ${ }^{1}$ \\ ${ }^{1}$ School of Civil Engineering, Central South University, Changsha, China \\ ${ }^{2}$ China Construction Fifth Engineering Division Crop., Ltd., Changsha, China \\ ${ }^{3}$ School of Civil Engineering, Sun Yat-Sen University, Guangzhou, China \\ Correspondence should be addressed to Jianjun Ma; jianjun_ma@wzu.edu.cn
}

Received 23 May 2018; Accepted 24 July 2018; Published 26 August 2018

Academic Editor: Jian Sun

Copyright ( $\odot 2018$ Mingfeng Lei et al. This is an open access article distributed under the Creative Commons Attribution License, which permits unrestricted use, distribution, and reproduction in any medium, provided the original work is properly cited.

\begin{abstract}
A heterogeneous equivalent beam model (HEB model) of the shield tunnel segment structure is proposed based on a systematical analysis on the stress state of the cross section of segment joints. This model treats a noncontinuous segment structure as a continuous heterogeneous structure, on the basis of the principle of equivalent stress state on a section and equivalent conversion of the mechanical parameters. For a comprehensive demonstration of the proposed HEB model, an interpretative solution of equivalent mechanical parameters of the joint section is obtained through theoretical derivation, and a specific iterative computation flow is provided in accordance. Model validation and comparative analysis are also conducted for two industrial applications. It is found that the iterative process of calculation has good convergence, leading to reliable numerical results for all cases under consideration. Resulting simulations reveal that the proposed HEB model can reflect the effect of joints on overall rigidity of a segment structure. Compared with the computation results obtained using other models presented in the literature, there are smaller axial force deviation and larger bending moment deviation (up to $20 \%$ or higher), demonstrating that the model selection is important in design and computation of a segment structure of shield tunnels. The proposed model and analysis for model performance may provide useful reference for engineers in shield tunnel community.
\end{abstract}

\section{Introduction}

Shield technique has been widely applied in the construction of urban subway and underwater tunnels owing to its high level of mechanization, rapid construction, and minimal environmental impact $[1,2]$. The design of the segment structure is of critical importance for the application of shield technique and project construction, in terms of both the safety of tunnel structure and construction cost. $\mathrm{Nu}-$ merous engineering reports show that segmental lining accounts for $30 \%$ to $50 \%$ of the total cost of a tunnel constructed by shield technique [3].

Unlike traditional monolithic tunnel lining structures, segmental lining is a noncontinuous structure with vertical and transverse joints. The mechanical behavior of each segment is affected by structural and mechanical characteristics of joints [4]. Therefore, segmental lining is more complex, as both calculation and analysis of the stress state is much more difficult than monolithic lining. In the open literature, comprehensive studies on the calculation model for shield segment structure have been conducted.

In 1978, International Tunneling Association (ITA) established a specialized team for collecting calculation models for shield tunnel segments. ITA supplemented updated data according to the industrial development. The published summary in 1988 shows that the design model for tunnel structure at that time covers continuum or noncontinuum models, elastic foundation beam models, convergence-constraint models, and empirical methods $[5,6]$.

In recent decades, along with the massive development of urban rail transportation, studies on the calculation model of shield tunnel segment have made a great progress. Multiple structural calculation models, including uniform rigidity ring model (UR model), modified uniform rigidity ring model (MUR model), free hinge ring model, 
beam-spring model, and beam-joint model, have been proposed [7], as shown in Figure 1.

Ye et al. [8] comprehensively analyzed the performance of these calculation models for the shield tunnel segment. They found that the UR model completely ignores the effect of segmental joint, which is obviously different from the actual situation. This model results in higher internal force of the hard formation and relatively less deformation of the weak formation, leading to increased security risks [8]. The MUR model is carried out by reducing the segment stiffness and increasing bending moment coefficients, resulting in greater randomness and uncertainty [9-12]. The free hinge ring model takes the segment joint as a single-hinge structure and thus does not reflect the properties of force transfer on the joint section. In addition, this model is a nonstatic system, although it can provide a static solution with the support of a tunnel surrounding rock, the ground resistance of tunnel surrounding rock cannot be calculated, and therefore, this model is characterized by certain levels of limitations and uncertainty [13]. In fact, the beam-spring model and the beam-joint model can better reflect the effect of segment joint on the stiffness of the whole ring structure. However, the theoretical basis for selecting the spring coefficient has not been well investigated; thus the spring coefficient is estimated based on the model test or engineering experience, leading to a certain level of randomness in modelling results $[12,14,15]$.

Although the design, calculation, and modelling of shield tunnel segment structures have attracted considerable attentions, a variety of problems still need further investigation. Based on comprehensive analysis on the stress characteristics and the properties of force transfer on the joint between shield tunnel segments, the current study converts a noncontinuous segment structure into a continuous heterogeneous equivalent beam structure through equivalent conversion of mechanical parameters of the joint section. Mechanical parameters of the joint section are also deduced under different working conditions to establish a new calculation model for the shield tunnel segment. This model is significant, as it treats the noncontinuous shield segment joint as an equivalent continuous structure with only tiny changes on the mechanical and deformation characteristics; and most importantly, it is capable to capture the stress characteristics and the properties of force transfer on the joint comprehensively. The performance of this model has been demonstrated through two industrial applications from the literature. The proposed HEB model and the comprehensive analysis presented for the HEB model may provide useful reference for engineers and scholars in the community of shield tunnel construction.

\section{Establishment and Basic Idea of HEB Model}

Engineering practice and theoretical studies show that the section of a segment joint is used to maintain the balance of internal force and transfer forces, which is similar to the force-transferring property of reinforced concrete cross section [1]. Therefore, the segment joints and the partial structures in their local range can be regarded as a beam element. However, the cross-sectional parameters of a beam element (i.e., elastic modulus and geometrical parameters) are different from those of a segment section. Based on this idea, the HEB model with segment ring composed of the beam element is established, as shown in Figure 2. In this model, parameters of the section in the local range of joint are converted equivalently according to the actual stress state on the section of joint.

\section{Analysis on Mechanical Properties of Equivalent Beam Element of Joint}

3.1. Basic Assumptions. In the mechanical calculation of the shield segment structure, a shield segment is always taken as a bending element; that is, only its bending moment and axial force are considered. The finite element method is normally applied to calculate the distribution of internal forces on each cross section. Then, the damage phase method in which the shear properties are neglected is employed to check its bearing capacity. Studies on the beam-spring model showed that if the shear stiffness of a circular joint is set to be smaller, the bending moment of its main cross section turns out to be smaller accordingly. Therefore, for security considerations, the shear stiffness of circular joints is usually set to be infinite [16]. This means that mechanical properties of a joint equivalent beam element only rely on the crosssectional parameter of its longitudinal joint. As such, the following hypotheses are applied:

(1) Shearing stiffness of bolt and friction of section can effectively resist shear force at the joint; that is, no obvious deformation is generated in both sides of the joint [17].

(2) Based on structural mechanics, only the effect of axial force and bending moment on the displacement of arch structure is considered (i.e., the effect of shear stiffness is ignored).

(3) The deformation of joint section complies with the plane section assumption in all planes and meets the deformation compatibility.

(4) The stress of the concrete at the end of a joint is distributed linearly in the form of trapezoid and triangle shapes, respectively, corresponding to fully contact (original joint section) and opening states (partial loss of contact) of a joint connection during service life.

(5) Compressive deformation $\delta_{0}$ of the compressed concrete at segment joint obeys the following equation $[18-20]$ :

$$
\delta_{0}=\frac{\sigma x}{E_{\mathrm{c}}},
$$

where $E_{\mathrm{c}}$ is the elastic modulus of concrete, $\sigma$ is the maximum compressive stress at the edge of concrete, and $x$ is the effective height of compressed area of a joint section. 


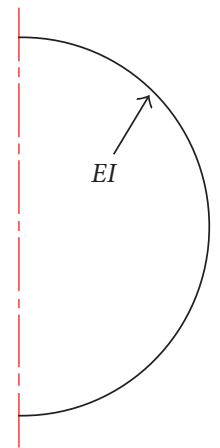

(a)

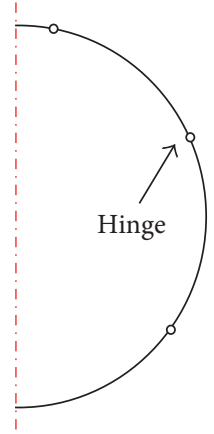

(c)

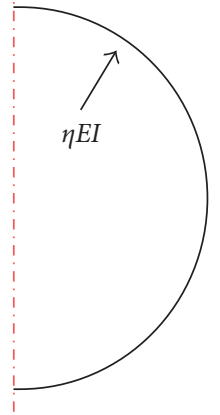

(b)

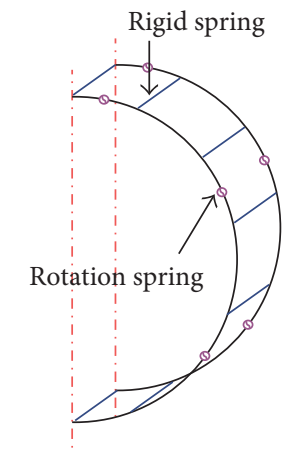

(d)

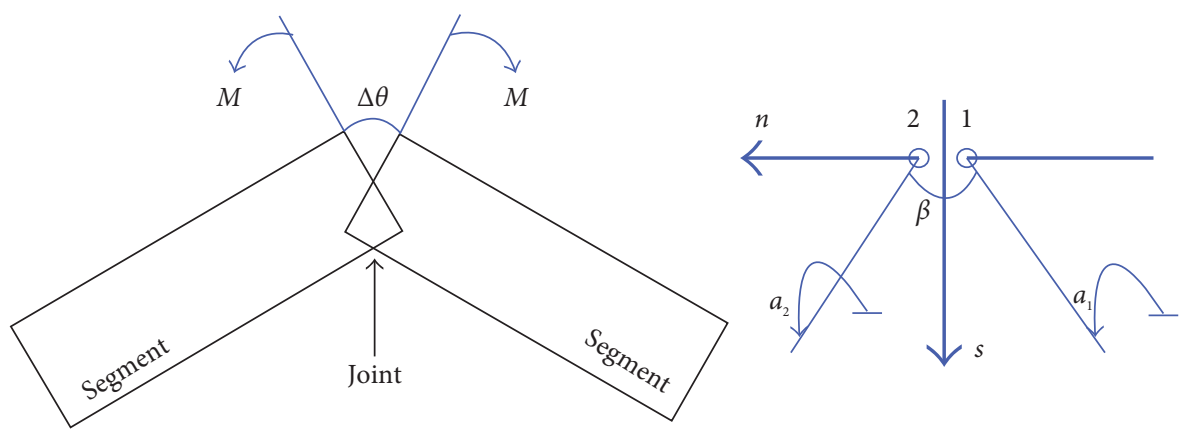

(e)

FIGURE 1: Structural models of the shield segment [7]. (a) UR model. (b) MUR model. (c) Free hinge ring model. (d) Beam-spring model. (e) Beam-joint model.

\subsection{Positive Bending Moment and Small Eccentric Compression}

3.2.1. Stress Characteristics of the Original Section. A segment joint force diagram under positive bending moment and small eccentric compression is shown in Figure 3(a); assuming the stress in the diagram is positive, the following equations can be obtained based on static equilibrium:

$$
\begin{aligned}
& \sum F=0, N=\frac{b h}{2}\left(\sigma_{c, \text { max }}+\sigma_{c, \min }\right)-n T_{\mathrm{b}}, \\
& \sum M=0, M=\frac{b h^{2}}{12}\left(\sigma_{c, \max }-\sigma_{c, \min }\right)+n T_{\mathrm{b}}\left(\frac{h}{2}-h_{0}\right),
\end{aligned}
$$

where $N$ and $M$ are the axial force and bending moment of the section, respectively; $\sigma_{c, \max }$ and $\sigma_{c, \text { min }}$ refer to the compressive stress outside and inside the joint section, respectively; $h$ and $b$ refer to the thickness and width of the segment, respectively; $n$ is the number of bolts in this segment; $T_{\mathrm{b}}$ is the pulling force of a single bolt; and $h_{0}$ is the distance from the centroid of bolt to the internal edge. The deformation compatibility and plane cross-sectional assumption can be applied to solve the strain at bolt:

$$
\varepsilon_{\mathrm{b}}=\varepsilon_{\mathrm{c}, \min }+\frac{h_{0}}{h}\left(\varepsilon_{\mathrm{c}, \max }-\varepsilon_{\mathrm{c}, \min }\right)
$$

where $\varepsilon_{\mathrm{b}}$ is the strain at bolt in the joint section and $\varepsilon_{c, \text { max }}$ and $\varepsilon_{c, \text { min }}$ refer to the inside and outside edge strains of concrete in the joint section, respectively. 


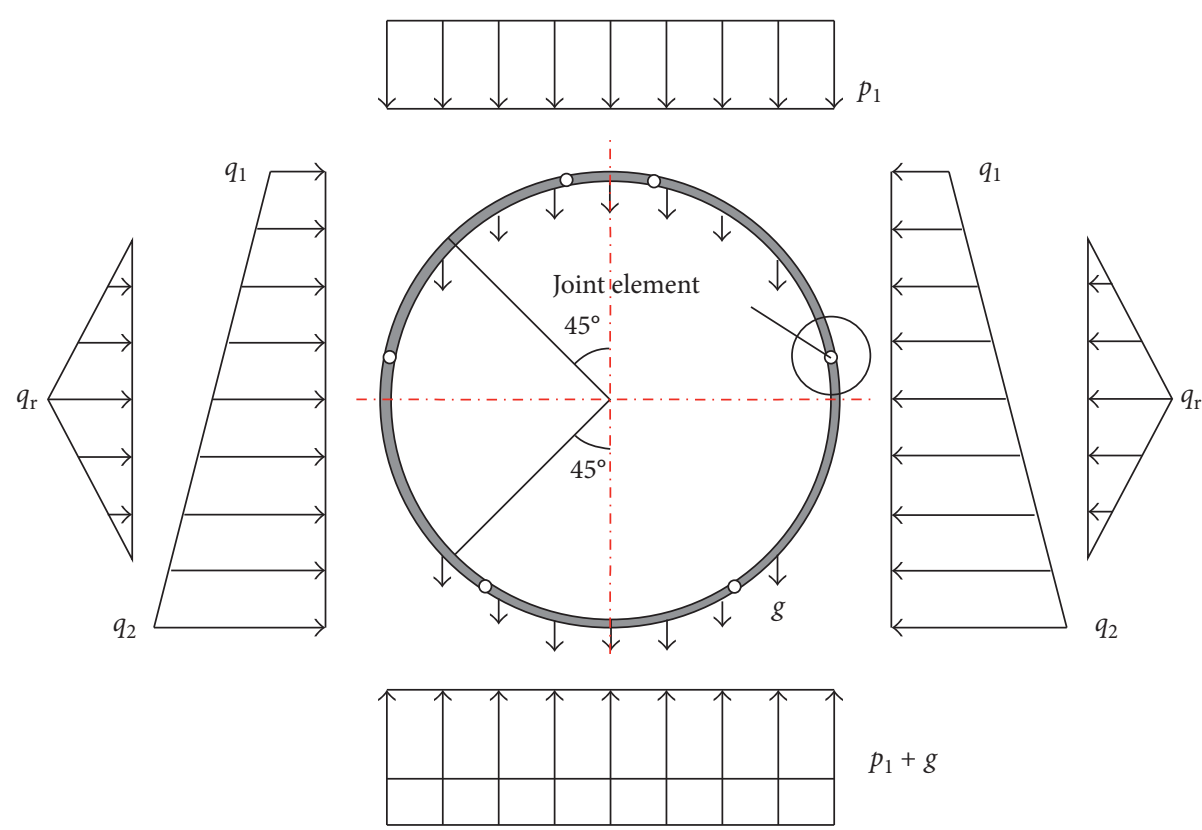

(a)

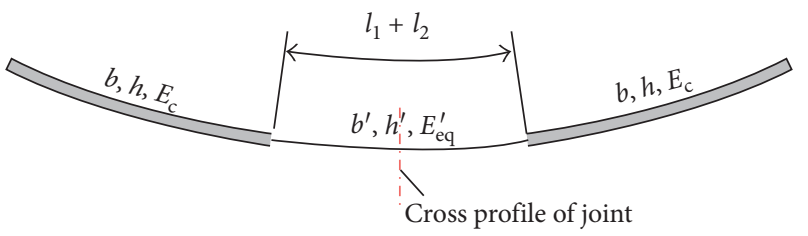

(b)

FIGURE 2: Structural calculation model of shield tunnel segment with HEB model: (a) Structural calculation model; (b) Equivalent beam element of joint.

A joint section consists of concrete, sealing rubber stripe, and force transferring cushion. Therefore, the elastic modulus of this composite section needs to be calculated based on the principle of equivalence. As shown in Figure 4, its compressive deformation properties are

$$
\frac{N\left(l_{1}+l_{2}\right)}{E_{\mathrm{eq}} A}=\frac{N l_{1}}{E_{\mathrm{c}} A}+\frac{N l_{2}}{E_{\mathrm{p}} A}
$$

where $E_{\text {eq }}$ is the equivalent compressive elastic modulus of the joint beam element; $A$ is the cross-sectional area; $l_{1}$ is the length of the concrete section for joint section calculation, and it takes twice the cover thickness of concrete for protection, which depends on the working environment and structure type; $l_{2}$ is the thickness of the sealing rubber strip and force transferring cushion, and it can be taken as $5 \mathrm{~mm}$ in most circumstances; and $E_{\mathrm{p}}$ is the elastic modulus of the sealing rubber strip and force transferring cushion. Thus, the equivalent elastic modulus of the joint section can be obtained:

$$
E_{\mathrm{eq}}=\frac{E_{\mathrm{c}} E_{\mathrm{p}}\left(l_{1}+l_{2}\right)}{E_{\mathrm{c}} l_{1}+E_{\mathrm{p}} l_{2}} .
$$

Therefore, in (3), $\varepsilon_{c, \text { max }}$ and $\varepsilon_{c, \text { min }}$ can be expressed as

$$
\begin{aligned}
& \varepsilon_{\mathrm{c}, \max }=\frac{\sigma_{\mathrm{c}, \max }}{E_{\mathrm{eq}}}, \\
& \varepsilon_{\mathrm{c}, \text { min }}=\frac{\sigma_{\mathrm{c}, \min }}{E_{\mathrm{eq}}} .
\end{aligned}
$$

With further initial pretightening force of bolt, there is

$$
T_{0}-T_{\mathrm{b}}=\varepsilon_{\mathrm{b}} K
$$

where $K$ is the tensile stiffness of bolt, $K=E_{\mathrm{s}} A_{\mathrm{s}}$ in which $E_{\mathrm{s}}$ is the elastic modulus of bolt and $A_{s}$ is the sectional area of a single bolt, and $T_{0}$ is the initial pretightening force of the bolt.

Solving (3), (6), and (7) simultaneously,

$$
T_{\mathrm{b}}=T_{0}-\frac{K}{E_{\text {eq }}}\left[\sigma_{c, \text { min }}+\frac{h_{0}}{h}\left(\sigma_{c, \text { max }}-\sigma_{c, \min }\right)\right] .
$$

Then, considering (2) and (8)

$$
\begin{gathered}
\sigma_{c, \text { max }}=\frac{\lambda_{2} \lambda_{4}+\lambda_{1} \lambda_{6}}{\lambda_{3} \lambda_{6}+\lambda_{2} \lambda_{5}}, \\
\sigma_{c, \text { min }}=\frac{\lambda_{1} \lambda_{5}-\lambda_{3} \lambda_{4}}{\lambda_{3} \lambda_{6}+\lambda_{2} \lambda_{5}},
\end{gathered}
$$




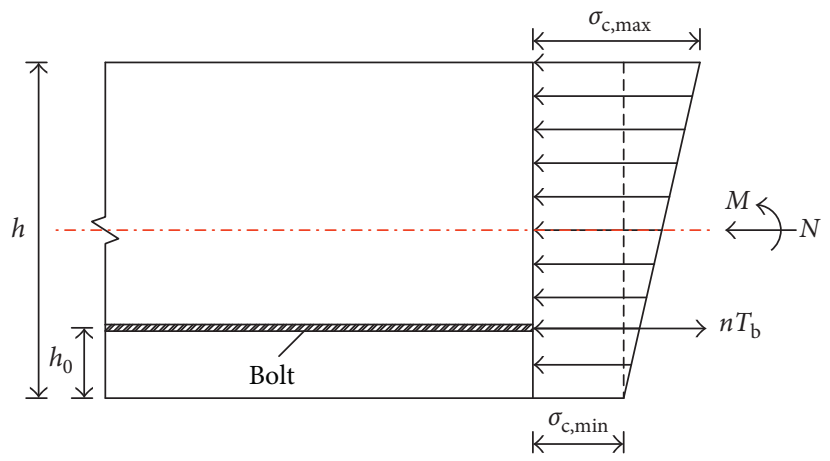

(a)

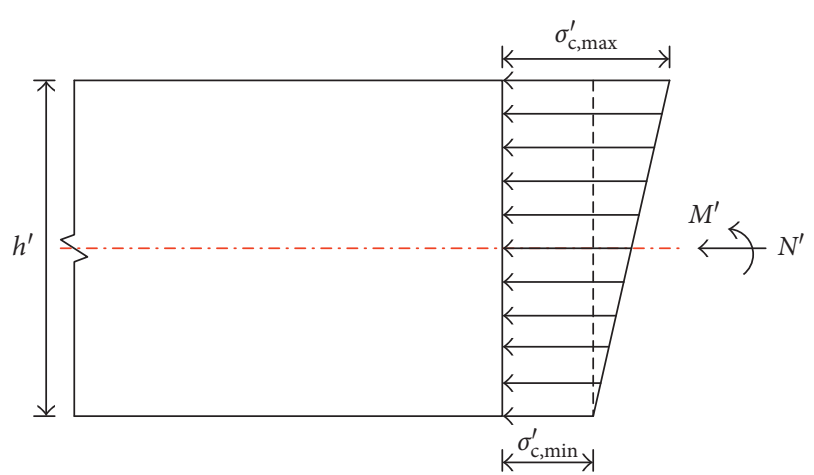

(b)

FIGURE 3: Mechanical characteristic of the joint section under positive bending moment and small eccentricity pressing condition. (a) Original joint section. (b) Equivalent joint section.

where

$$
\begin{aligned}
& \lambda_{1}=n T_{0}+N, \\
& \lambda_{2}=\frac{h b}{2}+\frac{n K}{E_{\mathrm{eq}}}\left(1-\frac{h_{0}}{h}\right), \\
& \lambda_{3}=\frac{h b}{2}+\frac{n K h_{0}}{E_{\mathrm{eq}} h}, \\
& \lambda_{4}=M-n T_{0}\left(\frac{h}{2}-h_{0}\right), \\
& \lambda_{5}=\frac{b h^{2}}{12}-\left(\frac{h}{2}-h_{0}\right) \frac{n K h_{0}}{E_{\mathrm{eq}} h}, \\
& \lambda_{6}=\frac{b h^{2}}{12}+\left(\frac{h}{2}-h_{0}\right)\left(1-\frac{h_{0}}{h}\right) \frac{n K}{E_{\mathrm{eq}}} .
\end{aligned}
$$

3.2.2. Stress Characteristics of the Equivalent Section. A stress analysis chart of the equivalent section under positive bending moment and small eccentric compression can be established based on the equivalent principle of the stress state of cross section, as shown in Figure 3(b). Based on the equilibrium relationship of force, there is

$$
\begin{aligned}
& N^{\prime}=\frac{b^{\prime} h^{\prime}}{2}\left(\sigma_{c, \text { max }}^{\prime}+\sigma_{c, \text { min }}^{\prime}\right), \\
& M^{\prime}=\frac{b^{\prime} h^{\prime 2}}{12}\left(\sigma_{c, \text { max }}^{\prime}-\sigma_{c, \text { min }}^{\prime}\right),
\end{aligned}
$$

where $N^{\prime}$ and $M^{\prime}$ refer to the axial force and bending moment of the section of an equivalent beam element, respectively; $\sigma_{c, \max }^{\prime}$ and $\sigma_{\mathrm{c}, \min }^{\prime}$ are outside and inside compressive stresses, respectively; and $h^{\prime}$ and $b^{\prime}$, respectively, refer to the height and calculation width of the equivalent beam section.

Based on the equivalent principle of the stress state of cross section, the internal force and rotation of the equivalent beam section are the same as those of the original section:

$$
\begin{aligned}
N^{\prime} & =N, \\
M^{\prime} & =M, \\
\frac{\left(\sigma_{\mathrm{c}, \text { max }}-\sigma_{\mathrm{c}, \text { min }}\right)}{E_{\mathrm{eq}}} & =\frac{\left(\sigma_{\mathrm{c}, \text { max }}^{\prime}-\sigma_{\mathrm{c}, \min }^{\prime}\right)}{E_{\mathrm{eq}}^{\prime}},
\end{aligned}
$$

where $E_{\mathrm{eq}}^{\prime}$ is the equivalent elastic modulus under positive bending moment and small eccentric compression of equivalent beam element.

For the total cross section compression, the height and width of the compressive area of an equivalent cross section are the same as those of the original cross section, that is, $b^{\prime}=b$ and $h^{\prime}=h$. By solving (11) and (12) simultaneously, the following relationship is obtained:

$$
E_{\mathrm{eq}}^{\prime}=\frac{12 M E_{\mathrm{eq}}}{b h^{2}\left(\sigma_{c, \text { max }}-\sigma_{c, \text { min }}\right)},
$$

where $E_{\text {eq }}^{\prime}$ is the elastic modulus of an equivalent beam, and it can be calculated from (9) and (13).

\subsection{Positive Bending Moment and Large \\ Eccentric Compression}

3.3.1. Stress Characteristics of the Original Section. A segment joint force diagram under positive bending moment and large eccentric compression is shown in Figure 5(a). The axial force and bending moment can be expressed as

$$
\begin{aligned}
& N=\frac{1}{2} \sigma_{c, \text { max }} b x-n T_{\mathrm{b}}, \\
& M=\frac{1}{12} \sigma_{c, \text { max }} b x\left(\frac{h}{2}-\frac{x}{3}\right)+n T_{\mathrm{b}}\left(\frac{h}{2}-h_{0}\right) .
\end{aligned}
$$

According to the assumption (4), the deformation at the edge of concrete is $\delta_{c, \max }=x \cdot \theta$. Similarly, the deformation at the bolt can be $\delta_{\mathrm{b}}=\left(h-h_{0}-x\right) \cdot \theta$. Here, $\theta$ is the opening angle of the joint.

Considering the initial pretightening force of bolt, axial force of bolt should meet the following relationship: 


$$
T_{\mathrm{b}}-T_{0}=\frac{\delta_{\mathrm{b}}}{L} K
$$

where $L$ is the effective calculation length of the bolt.

From the assumption (5), the deformation at the edge of the segment can be obtained:

$$
\delta_{c, \max }=\frac{\sigma_{\mathrm{c}, \max }}{E_{\mathrm{eq}}} \cdot x .
$$

Solving (14) and (16) simultaneously,

$$
C_{1} x^{2}+C_{2} x+C_{3}=0
$$

where

$$
\begin{aligned}
& C_{1}=\lambda_{2} \lambda_{5} \\
& C_{2}=\lambda_{3} \lambda_{5}-\lambda_{1} \lambda_{6} \\
& C_{3}=\lambda_{4} \lambda_{5}-\lambda_{1} \lambda_{7} \\
& \lambda_{1}=M-n T_{0}\left(\frac{h}{2}-h_{0}\right) \\
& \lambda_{2}=-\frac{b}{6}, \\
& \lambda_{3}=\frac{b h}{4}-\frac{n K}{E_{\mathrm{eq}} L}\left(\frac{h}{2}-h_{0}\right) \\
& \lambda_{4}=\frac{n K}{E_{\mathrm{eq}} L}\left(\frac{h}{2}-h_{0}\right)\left(h-h_{0}\right), \\
& \lambda_{5}=N+n T_{0}, \\
& \lambda_{6}=\frac{b}{2}+\frac{n K}{E_{\mathrm{eq}} L}, \\
& \lambda_{7}=-\frac{n K}{E_{\mathrm{eq}} L}\left(h-h_{0}\right) .
\end{aligned}
$$

Equation (17) shows the function of the height of the compressed area $x$. The height of the compressed area $x$ under corresponding force can be obtained by substituting the relative parameter with the range of $x$, that is, $x \in[0, h]$. Then, the maximum compression at the edge of segment $\sigma_{c, \max }$ can be obtained

$$
\begin{aligned}
\sigma_{c, \text { max }} & =\frac{\lambda_{1}}{\lambda_{2} x^{2}+\lambda_{3} x+\lambda_{4}}, \\
\text { or } \sigma_{c, \text { max }} & =\frac{\lambda_{5}}{\lambda_{6} x+\lambda_{7}} .
\end{aligned}
$$

3.3.2. Stress Characteristics of the Equivalent Section. A stress analysis diagram of the equivalent section under positive bending moment and large eccentric compression is

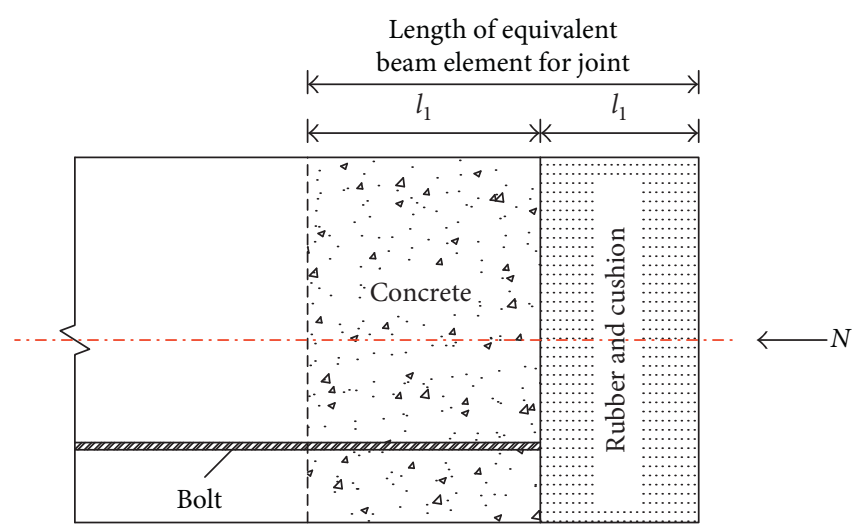

Figure 4: Analysis of the equivalent elastic modulus on the joint section.

shown in Figure 5(b), which can be obtained from static equilibrium:

$$
\begin{aligned}
& N^{\prime}=\frac{1}{2} \sigma_{c, \text { max }}^{\prime} b^{\prime} x^{\prime}-\frac{1}{2} \sigma_{c, \min }^{\prime} b^{\prime}\left(h^{\prime}-x^{\prime}\right), \\
& M^{\prime}=\frac{1}{2} \sigma_{c, \text { max }}^{\prime} b^{\prime} x^{\prime}\left(\frac{h^{\prime}}{2}-\frac{x^{\prime}}{3}\right)+\frac{1}{2} \sigma_{c, \text { min }}^{\prime} b^{\prime}\left(h^{\prime}-x^{\prime}\right)\left(\frac{h^{\prime}}{6}+\frac{x^{\prime}}{3}\right) .
\end{aligned}
$$

Given that the stress property of the equivalent section is the same as that of the original section:

$$
\begin{aligned}
N^{\prime} & =N, \\
M^{\prime} & =M, \\
\frac{\sigma_{c, \text { max }}^{\prime}}{E_{\mathrm{eq}}^{\prime} x^{\prime}} & =\frac{\sigma_{c, \text { min }}^{\prime}}{E_{\mathrm{eq}}^{\prime}\left(h^{\prime}-x^{\prime}\right)} .
\end{aligned}
$$

Two conditions should be added to solve the equation system consisting of (20) and (21) They are (1) composition of forces in the tensile zone of the equivalent section is the same as the pulling force of bolt in the original section and (2) the width of the equivalent section is obtained according to the ratio of the area of bolt to the area of the internal reinforcement of segmental lining $\alpha_{\mathrm{cs}}$. Thus,

$$
\begin{aligned}
n T_{\mathrm{b}} & =\frac{1}{2} \sigma_{\mathrm{c}, \min }^{\prime} b^{\prime}\left(h^{\prime}-x^{\prime}\right), \\
b^{\prime} & =\alpha_{\mathrm{cs}} b .
\end{aligned}
$$

By solving (20), (21), and (22) simultaneously, the mechanical parameters of the equivalent section under positive bending moment and large eccentric compression can be obtained:

$$
\begin{aligned}
x^{\prime} & =\frac{M}{\lambda_{1} \lambda_{2}-(N / 3)}, \\
h^{\prime} & =\lambda_{1} x^{\prime}, \\
E_{e q}^{\prime} & =\frac{2 n E_{\mathrm{eq}} T_{\mathrm{b}} x}{\alpha_{\mathrm{cs}} b \sigma_{\mathrm{c}, \max }\left(h^{\prime}-x^{\prime}\right)^{2}},
\end{aligned}
$$


where

$$
\begin{aligned}
& \lambda_{1}=\sqrt{\frac{n T_{\mathrm{b}}}{N+n T_{\mathrm{b}}}}+1, \\
& \lambda_{2}=\frac{N}{2}+\frac{2 n T_{\mathrm{b}}}{3} .
\end{aligned}
$$

\subsection{Negative Bending Moment and Small \\ Eccentric Compression}

3.4.1. Stress Characteristics of the Original Section. A stress analysis diagram of the segment joint section under negative bending moment and small eccentric compression is shown in Figure 6(a). It can be obtained from the following static equilibrium:

$$
\begin{aligned}
& N=\frac{b h}{2}\left(\sigma_{c, \max }+\sigma_{c, \min }\right)-n T_{\mathrm{b}}, \\
& M=-\frac{b h^{2}}{12}\left(\sigma_{c, \max }-\sigma_{c, \min }\right)+n T_{\mathrm{b}}\left(\frac{h}{2}-h_{0}\right) .
\end{aligned}
$$
strain is

According to deformation compatibility, the bolt

$$
\varepsilon_{\mathrm{b}}=\varepsilon_{c, \text { min }}+\frac{h-h_{0}}{h}\left(\varepsilon_{\mathrm{c}, \max }-\varepsilon_{c, \min }\right) .
$$

Solving (25) and (26) simultaneously, the following equation can be obtained:

$$
\begin{gathered}
\sigma_{c, \text { min }}=\frac{\lambda_{1} \lambda_{5}-\lambda_{2} \lambda_{4}}{\lambda_{2} \lambda_{6}+\lambda_{3} \lambda_{5}}, \\
\sigma_{c, \text { max }}=\frac{\lambda_{1} \lambda_{6}+\lambda_{4} \lambda_{3}}{\lambda_{2} \lambda_{6}+\lambda_{3} \lambda_{5}},
\end{gathered}
$$

where

$$
\begin{aligned}
& \lambda_{1}=n T_{0}+N, \\
& \lambda_{2}=\frac{1}{2} b h+\frac{n K}{E_{\mathrm{eq}}}\left(1-\frac{h_{0}}{h}\right), \\
& \lambda_{3}=\frac{1}{2} b h+\frac{h_{0} n K}{E_{\mathrm{eq}} h}, \\
& \lambda_{4}=n T_{0}\left(\frac{h}{2}-h_{0}\right)-M, \\
& \lambda_{5}=\frac{1}{12} b h^{2}+\frac{n K}{E_{\mathrm{eq}}}\left(1-\frac{h_{0}}{h}\right)\left(\frac{h}{2}-h_{0}\right), \\
& \lambda_{6}=\frac{1}{12} b h^{2}-\frac{n K h_{0}}{E_{\mathrm{eq}} h}\left(\frac{h}{2}-h_{0}\right) .
\end{aligned}
$$

3.4.2. Stress Characteristics of the Equivalent Section. Stress characteristics of the equivalent section under negative bending moment and small eccentric compression is shown in Figure 6(b). From static equilibrium and equivalent principle, we obtain

$$
\begin{aligned}
N^{\prime} & =\frac{b^{\prime} h^{\prime}}{2}\left(\sigma_{c, \text { max }}^{\prime}+\sigma_{c, \text { min }}^{\prime}\right), \\
M^{\prime} & =\frac{b^{\prime} h^{\prime 2}}{12}\left(\sigma_{c, \text { max }}^{\prime}-\sigma_{c, \text { min }}^{\prime}\right), \\
N^{\prime} & =N, \\
M^{\prime} & =M, \\
\frac{\left(\sigma_{c, \text { max }}-\sigma_{c, \text { min }}\right)}{E_{\mathrm{eq}}} & =\frac{\left(\sigma_{c, \max }^{\prime}-\sigma_{c, \text { min }}^{\prime}\right)}{E_{\mathrm{eq}}^{\prime}} .
\end{aligned}
$$

In addition, considering the width and height of the equivalent section $b^{\prime}=b$ and $h^{\prime}=h$, the following relationship can be obtained through (29) and (30):

$$
E_{\mathrm{eq}}^{\prime}=\frac{12 M E_{\mathrm{eq}}}{b h^{2}\left(\sigma_{c, \text { max }}-\sigma_{c, \text { min }}\right)} .
$$

\subsection{Negative Bending Moment and Large Eccentric Compression}

3.5.1. Stress Characteristics of the Original Section. Stress characteristics of the original section under negative bending moment and large eccentric compression can be further divided into two circumstances, as shown in Figures 7(a) and 7(b), according to the size of eccentricity.

(1) The 1st Circumstance. As shown in Figure 7(a), based on static equilibrium, we know that

$$
\begin{aligned}
& N=\frac{1}{2} \sigma_{c, \max } b x-n T_{\mathrm{b}}, \\
& M=-\frac{1}{2} \sigma_{c, \max } b x\left(\frac{h}{2}-\frac{x}{3}\right)+n T_{\mathrm{b}}\left(\frac{h}{2}-h_{0}\right) .
\end{aligned}
$$

From the plane section assumption, the deformation at bolt can be obtained as

$$
\varepsilon_{\mathrm{b}}=\frac{x-h_{0}}{x} \varepsilon_{\mathrm{c}, \max } .
$$

By solving (32) and (33) simultaneously, the following can be obtained:

$$
\lambda_{3} x^{2}-\lambda_{4} x-\frac{\lambda_{5}}{x}+\lambda_{2}=0,
$$




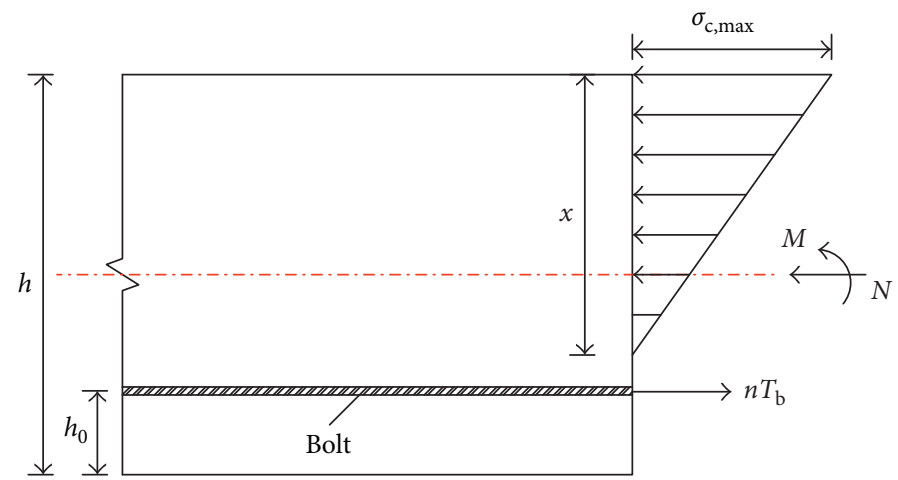

(a)

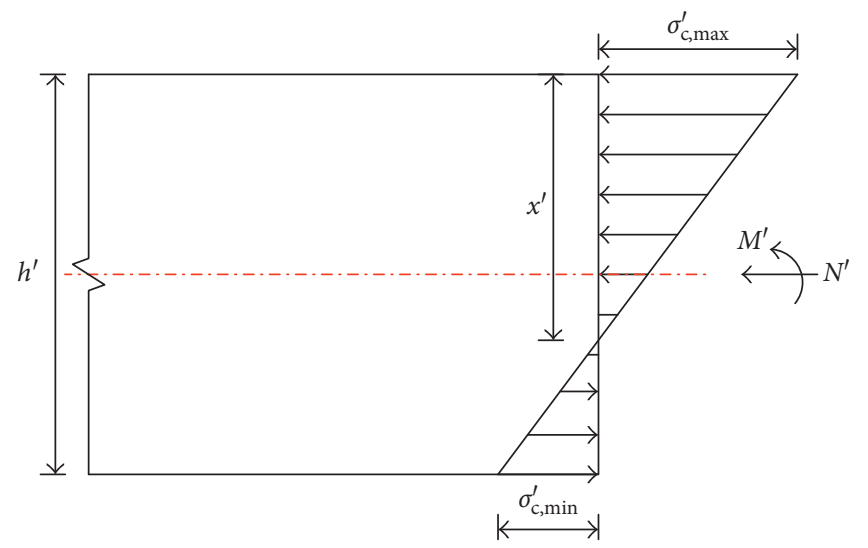

(b)

Figure 5: Mechanical characteristic of the joint section under positive bending moment and large eccentricity pressing condition. (a) Original joint section. (b) Equivalent joint section.

where

$$
\begin{aligned}
& \lambda_{1}=\frac{N+n T_{0}}{n T_{0}\left((h / 2)-\mathrm{h}_{0}-\mathrm{M}\right)}, \\
& \lambda_{2}=\frac{n K}{E_{\mathrm{eq}}}\left[\lambda_{1}\left(\frac{h}{2}-h_{0}\right)-1\right], \\
& \lambda_{3}=\frac{b \lambda_{1}}{6} \\
& \lambda_{4}=\frac{b}{2}+\frac{b h \lambda_{1}}{4}, \\
& \lambda_{5}=\lambda_{2} h_{0} .
\end{aligned}
$$

Therefore, considering the range of $x$, that is, $x \in[0, h]$, from (34), the height $x, \sigma_{\mathrm{c} \text { max }}$, and $T_{\mathrm{b}}$ of the compressed area of the internal concrete of a segment under negative bending moment and large eccentric compression can be obtained:

$$
\begin{aligned}
\sigma_{\mathrm{c}, \max } & =\frac{N+n T_{0}}{(1 / 2) \mathrm{bx}+\left(\mathrm{nK} / \mathrm{E}_{\mathrm{eq}}\right)\left(1-\left(\mathrm{h}_{0} / \mathrm{x}\right)\right)}, \\
T_{\mathrm{b}} & =T_{0}-\frac{\sigma_{\mathrm{c}, \max } K}{E_{\mathrm{eq}}}\left(1-\frac{h_{0}}{x}\right) .
\end{aligned}
$$

(2) The 2nd Circumstance. The corresponding stress analysis diagram is shown in Figure $7($ b). Its static equilibrium conditions meet (32) and the deformation compatibility, that is,

$$
\begin{aligned}
\delta_{c, \text { max }} & =x \cdot \theta, \\
\delta_{\mathrm{b}} & =\left(h_{0}-x\right) \cdot \theta .
\end{aligned}
$$

Solving (32) and (37) simultaneously, we obtain

$$
\lambda_{3} x^{2}-\lambda_{4} x+\lambda_{5}=0
$$

where

$$
\begin{aligned}
& \lambda_{1}=\frac{N+n T_{0}}{M-n T_{0}\left((h / 2)-\mathrm{h}_{0}\right)}, \\
& \lambda_{2}=\frac{n K}{E_{\mathrm{eq}}}\left[\lambda_{1}\left(\frac{h}{2}-h_{0}\right)+1\right], \\
& \lambda_{3}=b \lambda_{1},
\end{aligned}
$$

$$
\lambda_{4}=\lambda_{2}+\frac{b}{2}+\frac{b h \lambda_{1}}{4}
$$$$
\lambda_{5}=\lambda_{2} h_{0}
$$ 


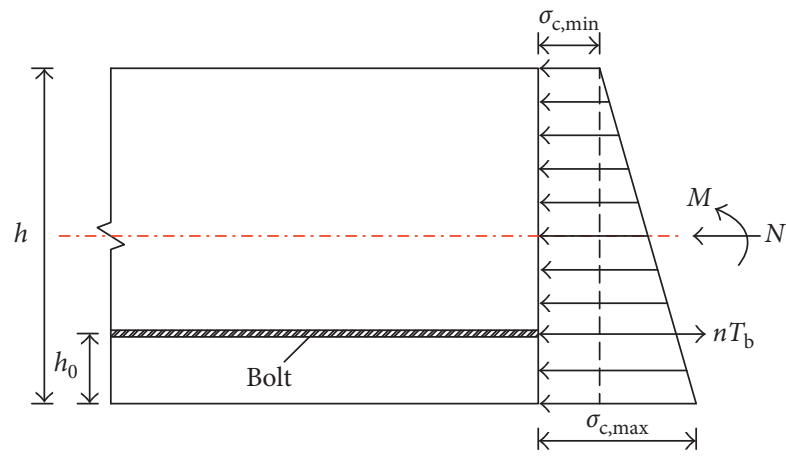

(a)

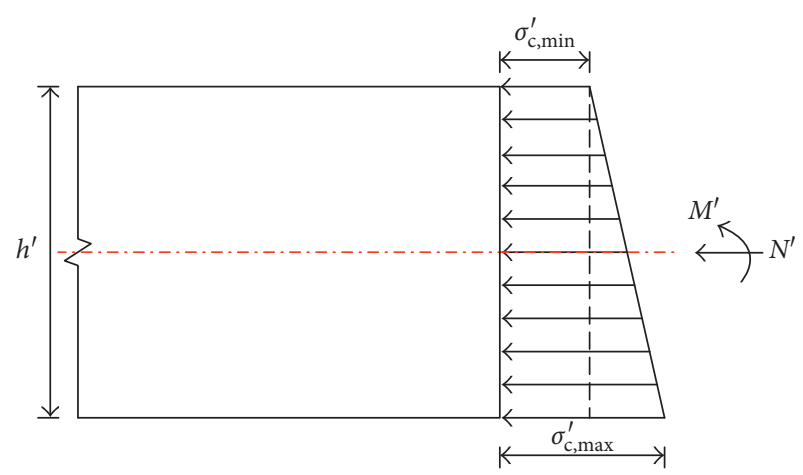

(b)

FIGURE 6: Mechanical characteristic of the joint section under positive bending moment and small eccentricity pressing condition. (a) Original joint section. (b) Equivalent joint section.

Therefore, considering the range of $x$, that is, $x \in\left[0, h_{0}\right]$, the height $x, \sigma_{c, \max }$, and $T_{\mathrm{b}}$ of the compressed area of the internal concrete of a segment under negative bending moment and large eccentric compression can be obtained using (38).

3.5.2. Stress Characteristics of the Equivalent Section. A diagram of the stress characteristics of the equivalent section under negative bending moment and large eccentric compression is shown in Figure 7(c). Based on static equilibrium and equivalent principle, we obtain

$$
\begin{aligned}
\sigma_{c, \text { min }} & =\frac{N^{\prime}}{b^{\prime} h^{\prime}}+\frac{6 M^{\prime}}{b^{\prime} h^{\prime 2}}, \\
\sigma_{c, \text { max }} & =\frac{N^{\prime}}{b^{\prime} h^{\prime}}-\frac{6 M^{\prime}}{b^{\prime} h^{\prime 2}}, \\
N^{\prime} & =N, \\
M^{\prime} & =M, \\
\frac{\sigma_{c, \text { max }}}{E_{\mathrm{eq}} x} & =\frac{\left(\sigma_{c, \text { max }}^{\prime}+\sigma_{c, \text { min }}^{\prime}\right)}{E_{\mathrm{eq}}^{\prime} h^{\prime}} .
\end{aligned}
$$

Similarly, solving (40) and (41) simultaneously, the following is obtained:

$$
E_{\mathrm{eq}}^{\prime} h^{\prime 2}=\frac{2 N E_{\mathrm{eq}} x}{\alpha_{\mathrm{cs}} b \sigma_{\mathrm{c}, \max }} .
$$

The height of the equivalent section under positive bending moment and large eccentric conditions can be used to calculate the height $h^{\prime}$ of the equivalent section under negative bending moment and large eccentric compression, as shown in (23). Thus, the elastic modulus of the equivalent beam under negative bending moment and large eccentric conditions can be obtained:

$$
E_{\mathrm{eq}}^{\prime}=\frac{2 N E_{\mathrm{eq}} x}{\alpha_{\mathrm{cs}} b \sigma_{\mathrm{c}, \max } h^{\prime 2}} .
$$

\section{Calculation Flow of HEB Model for Shield Tunnel Segment}

The derivation in Section 3 shows that the key idea of the HEB model is that the stress characteristics of a segment joint is analyzed through equating a joint section to a continuous beam element. That is, a noncontinuous segment structure is changed into a continuous heterogeneous beam structure. Also, section parameters of the equivalent beam at the joint should be obtained through equivalent conversion. The internal force of a joint section and initial physical and mechanical parameters should be obtained before any structural calculation. In this study, the UR model is used to estimate the internal force, and iterative calculation is applied to achieve accurate solution, with calculation flow being shown in Figure 8 .

\section{Model Validation and Applications}

5.1. Case 1. To verify the reliability of the proposed model, a comparative analysis is conducted by comparing model simulation with the result from the literature [21]. In this case, a certain interval of the shield tunnel, that is, number 3 Guangzhou subway in China, is used as an example. The segment structure of this interval of shield is designed as a " $3+2+1$ " block mode. The external diameter of the segment is $6.0 \mathrm{~m}$, and its thickness is $0.3 \mathrm{~m}$. The segment rings are connected through 2 high-tensile bolts (Class 8.8 M24) with initial pretightening force of $200 \mathrm{kN}$ and C50 concrete. The stratum is a weathered stratum in the red beds of Cretaceous System; the depth of tunnel is $22.14 \mathrm{~m}$, and the water level is $18.94 \mathrm{~m}$. The main parameters are shown in Figure 9(a).

\subsubsection{Calculation Process}

(1) First, with basic model parameters, applying the UR model (Figure 9(b)) to obtain the internal force of each joint section (Table 1). The load calculation takes both geological conditions and ground surcharge $p_{0}=20 \mathrm{kPa}$ into consideration. 


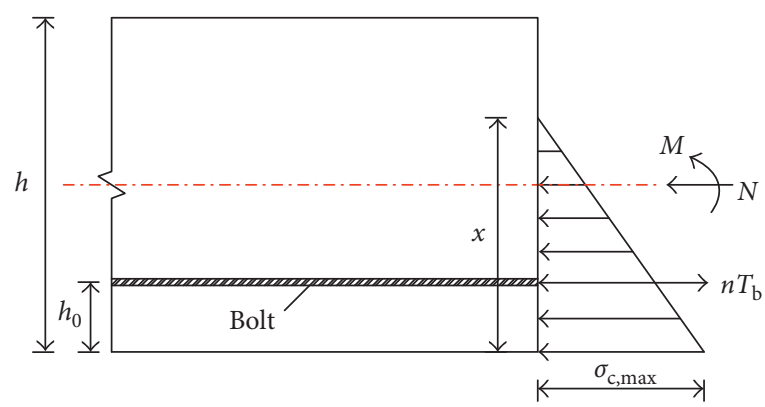

(a)

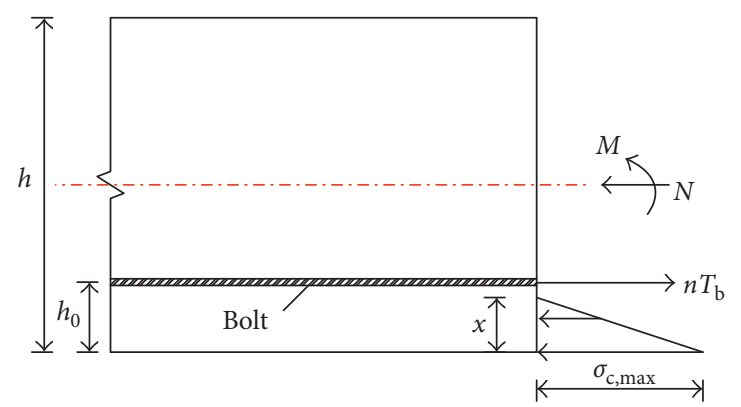

(b)

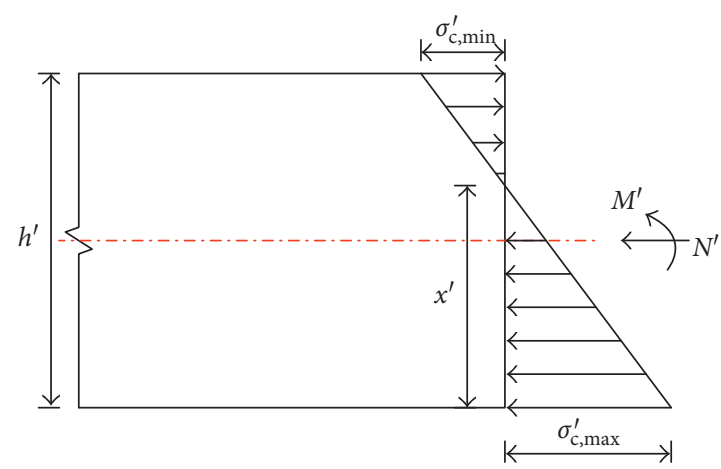

(c)

FIGURE 7: Mechanical characteristic of the joint section under hogging bending moment and large eccentricity pressing condition. (a) Original joint section with the first circumstance. (b) Original joint section with the second circumstance. (c) Equivalent joint section.

(2) The mechanical equivalent parameter solution of a joint section deduced according to Section 3 is used to solve the equivalent mechanical parameters of each section, as shown in Table 1.

(3) The equivalent mechanical parameters obtained in Step 2 is used to update those in Step 1. Then, repeating Steps 1-3 to obtain accurate results of the equivalent mechanical parameters. Accordingly, the internal force of the segment produced by the HEB model is obtained finally.

The final result of each joint section calculated is shown in Table 2. A very small difference in the calculation result of axial force is found between two models. However, the difference in bending moment is relatively large, with the maximum relative difference being about $8 \%$.

5.1.2. Comparative Analysis. The internal force on the vault section is used for comparative analysis, with results from the literature [21] and model simulation by this study being shown in Table 3. According to the principle of statistics, all kinds of methods for calculation are random events, and the mean value is closer to the true one. Thus, the mean values of simulation results and relative errors given by various methods are applied for comparative analysis.

The following results can be seen:

(1) For both bending moment and axial force, gaps between the HEB model results and the mean values are smaller than those of other methods, indicating that the HEB model may produce results closer to the true ones.

(2) The bending moment calculated using various methods are considerably different, whereas the change in axial force is relatively small. This means all models listed in Table 3 can meet the accuracy requirements of engineering applications in terms of axial force.

(3) Tables 1 and 3 show that the presence of a joint section lowers the stiffness of the joint section, thus resulting in a lower bearing bending moment in a joint compared with that of the UR model. By contrast, this value in the segment section is higher than that of the UR model, which is consistent with previous theoretical studies and engineering practice [8]. Therefore, the current model can better reflect the effect of joints on the stiffness of segment structure, and the model result is reliable.

5.2. Case 2. Lei et al. [22] introduced the construction of a shield tunnel in Guangzhou metro line 3, China. The diameter of this tunnel is $5.4 \mathrm{~m}$, constructed by earth pressure balance TBM, using precast reinforced concrete segments as inner lining (the diameter is $6 \mathrm{~m}$ ). The main geological conditions of tunnel section are filled soil, mucky soil, fine sand layer, diluvium and alluvium layer, and intense weathering mud rock. The stratum condition and parameters for calculation are listed in Table 4 and Figure 10, respectively. 


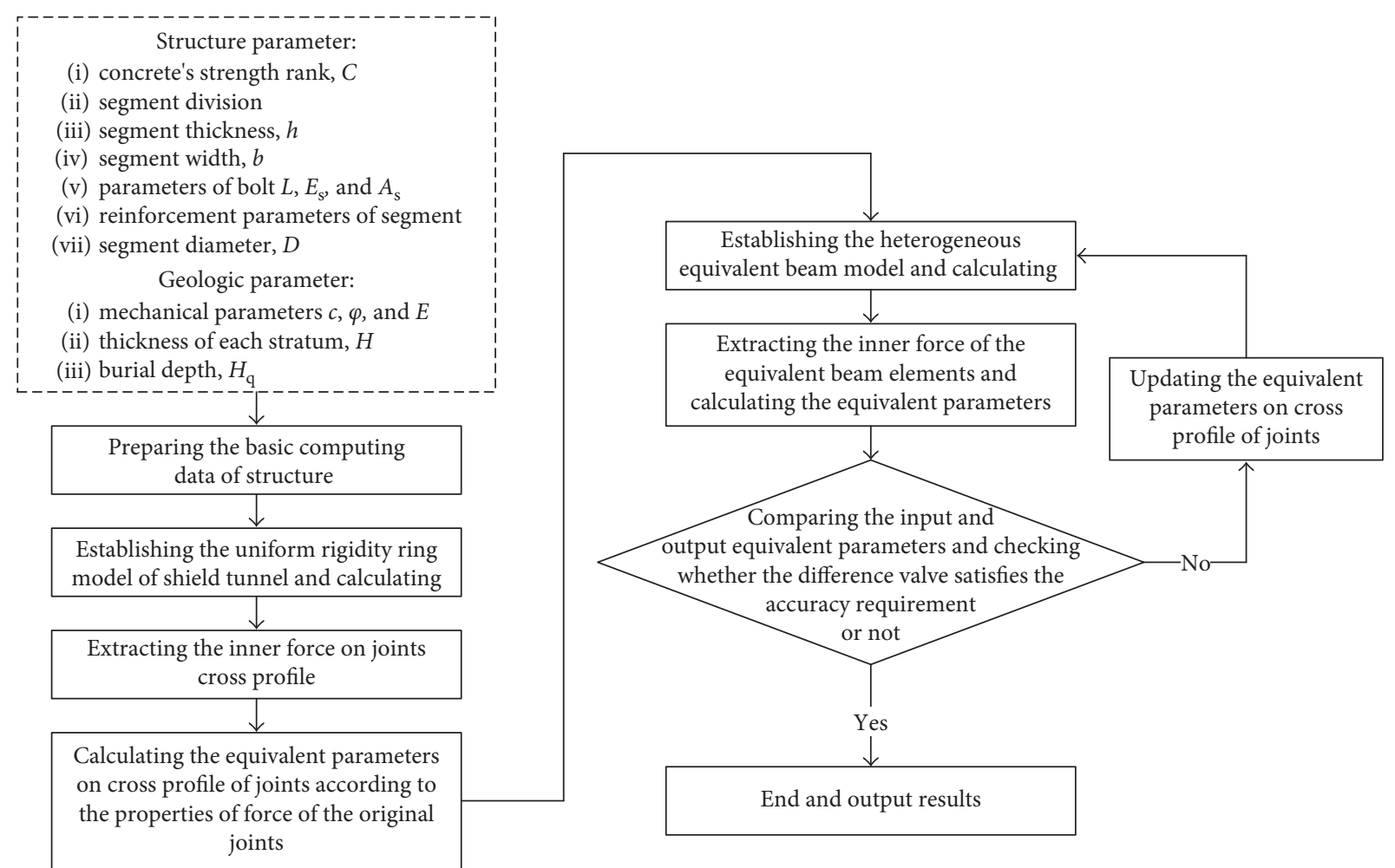

Figure 8: Calculation flow of the HEB model.
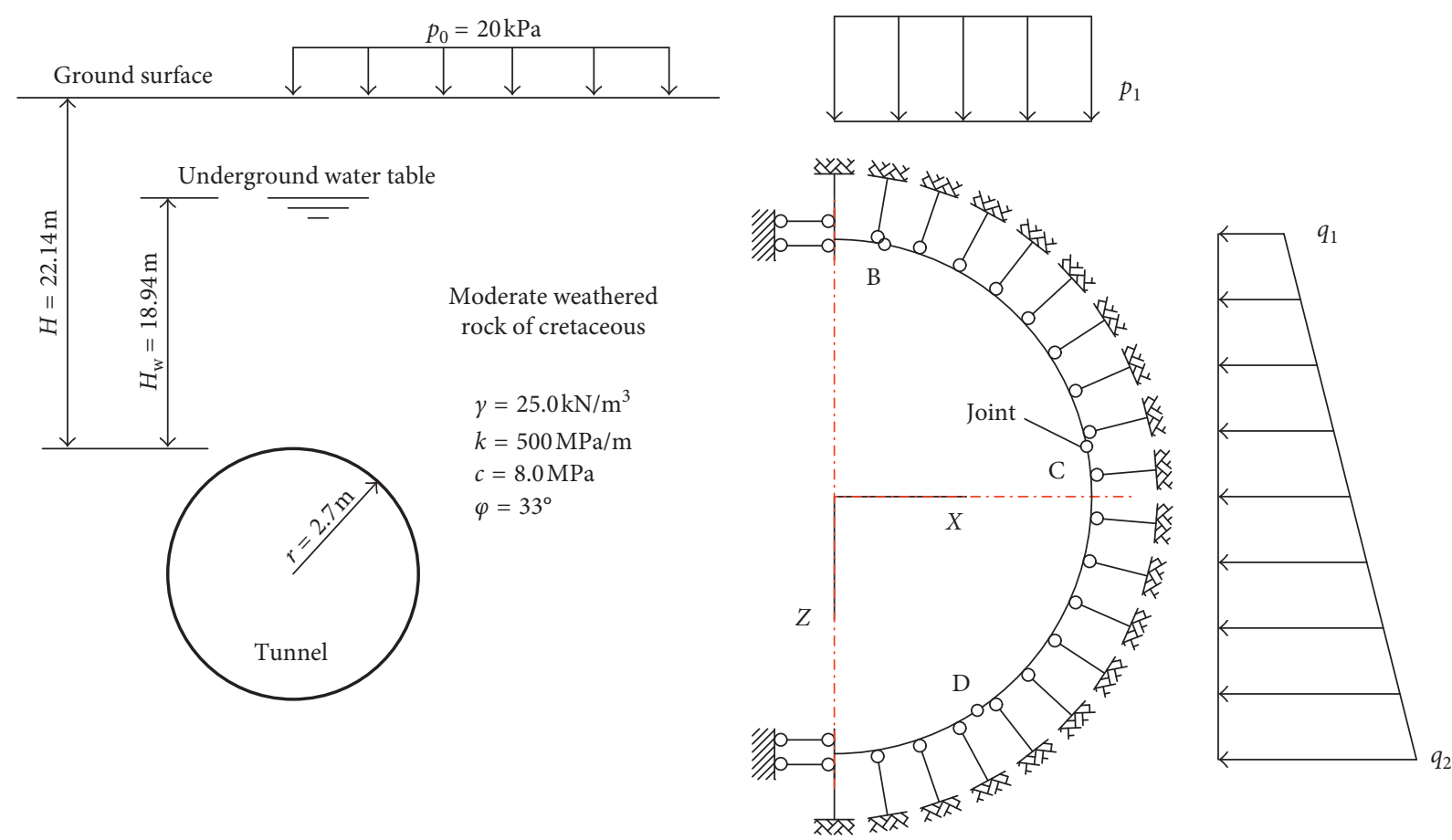

(a)

(b)

FIgure 9: Calculation model. (a) Geological condition. (b) Structural calculation model.

The relative literature and codes used in calculating the model parameters are shown in Table 5. The calculated parameters are then applied to establish a load-structure calculation model, as shown in Figure 9(b). For comparative analysis, the internal forces of the structure are calculated by the UR model, MUR model (stiffness reduction coefficient is 
TABLE 1: Equivalent parameters on joints section.

\begin{tabular}{|c|c|c|c|c|c|c|}
\hline \multirow[t]{2}{*}{ Joints } & \multicolumn{2}{|c|}{$\begin{array}{l}\text { Inner force evaluated by } \\
\text { UR model }\end{array}$} & \multirow[t]{2}{*}{ Force-bearing types } & \multicolumn{3}{|c|}{ Equivalent parameters } \\
\hline & $M(\mathrm{kN} \cdot \mathrm{m})$ & $N(\mathrm{kN})$ & & $h^{\prime}(\mathrm{m})$ & $b^{\prime}(\mathrm{m})$ & $E_{\mathrm{eq}}(\mathrm{GPa})$ \\
\hline B & 67.99 & 1354.51 & $\begin{array}{l}\text { Positive bending moment and small eccentricity } \\
\text { pressing }\end{array}$ & 0.3 & 1.5 & 7.36 \\
\hline $\mathrm{C}$ & -76.74 & 1566.17 & $\begin{array}{c}\text { Hogging bending moment and small eccentricity } \\
\text { pressing }\end{array}$ & 0.3 & 1.5 & 13.05 \\
\hline $\mathrm{D}$ & 31.94 & 2070.37 & $\begin{array}{c}\text { Positive bending moment and small eccentricity } \\
\text { pressing }\end{array}$ & 0.3 & 1.5 & 9.71 \\
\hline
\end{tabular}

TABLe 2: Calculation results of inner force on joints section.

\begin{tabular}{|c|c|c|c|c|c|c|}
\hline \multirow[t]{2}{*}{ Joints } & \multicolumn{2}{|c|}{ UR model } & \multicolumn{2}{|c|}{ HEB model } & \multicolumn{2}{|c|}{$\begin{array}{c}\text { Relative difference } \\
\text { value }(\%)\end{array}$} \\
\hline & $M(\mathrm{kN} \cdot \mathrm{m})$ & $N(\mathrm{kN})$ & $M(\mathrm{kN} \cdot \mathrm{m})$ & $N(\mathrm{kN})$ & $M$ & $N$ \\
\hline B & 67.99 & 1354.51 & 62.99 & 1355.62 & 7.94 & 0.08 \\
\hline $\mathrm{C}$ & -76.74 & 1566.17 & -79.26 & 1566.39 & 3.28 & 0.01 \\
\hline $\mathrm{D}$ & 31.94 & 2070.37 & 32.50 & 2045.25 & 1.75 & 1.23 \\
\hline
\end{tabular}

TABLE 3: Results comparison of inner force on crown section.

\begin{tabular}{|c|c|c|c|c|c|c|}
\hline \multirow[t]{2}{*}{ Calculation models } & \multirow[t]{2}{*}{$M(\mathrm{kN} \cdot \mathrm{m})$} & \multirow[t]{2}{*}{$N(\mathrm{kN})$} & \multicolumn{2}{|c|}{ Mean value } & \multicolumn{2}{|c|}{$\begin{array}{c}\text { Relative difference } \\
\text { value }(\%)\end{array}$} \\
\hline & & & $M(\mathrm{kN} \cdot \mathrm{m})$ & $N(\mathrm{kN})$ & $M$ & $N$ \\
\hline UR model & 76.94 & 1344.35 & \multirow{4}{*}{66.08} & \multirow{4}{*}{1347.79} & 16.43 & 0.26 \\
\hline MUR model & 77.10 & 1344.22 & & & 16.68 & 0.26 \\
\hline Multihinge ring mode & 38.40 & 1357.10 & & & 41.89 & 0.69 \\
\hline HEB model & 71.89 & 1345.48 & & & 8.79 & 0.17 \\
\hline
\end{tabular}

Note: the reduction coefficient in modified uniform rigidity model was selected as $\eta=0.7$.

TABLE 4: Calculation parameters of surrounding rock.

\begin{tabular}{lccc}
\hline Layer name & $\gamma\left(\mathrm{kN} \cdot \mathrm{m}^{-3}\right)$ & $\varphi\left({ }^{\circ}\right)$ & $c(\mathrm{kPa})$ \\
\hline Filled soil & 17.3 & 28 & 12 \\
Mucky soil, fine sand layer & 18.5 & 18 & 6 \\
Diluvium and alluvium layer & 19.5 & 20 & 1 \\
Intense weathering mud rock & 21.6 & 24 & 200 \\
\hline
\end{tabular}

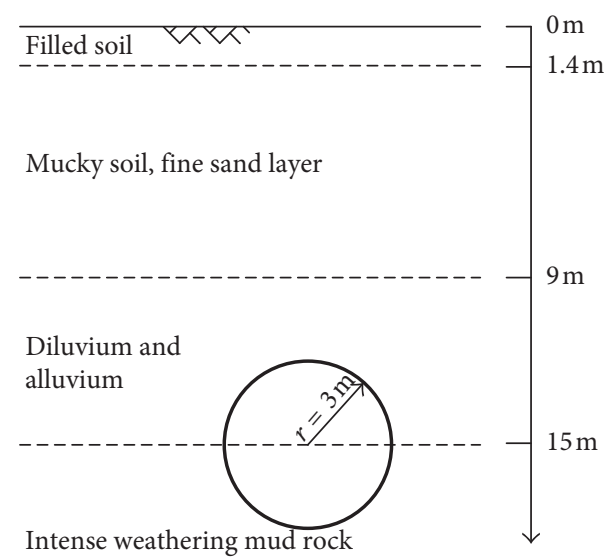

FIgURE 10: Tunnel depth and strata distribution for calculating.
0.7), and the proposed HEB model. For the HEB model, the calculation flow chart in Figure 8 is used for iterative calculation. The initial values are the same as those for a segment section. The iterative and convergence curves of the equivalent elastic modulus of all joints are shown as Figure 11. Results show that the proposed HEB model has good convergence in terms of the internal force calculation for shield segment structure. In addition, the proposed model can produce higher accuracy after 2-3 steps of iteration.

5.3. Analysis on Results. Figures 12 and 13 show the iteration process of the HEB model and the internal force distribution curve fluctuates associated with the update in mechanical parameters of a joint. With the increase of the iteration step, the simulation results approach a stable level gradually. Thus, this method has good convergence. The distribution laws of the final calculation results by three models are similar, coinciding with the theoretical studies and practical experience [8]. This indicates that the proposed HEB model is reliable.

The internal forces of joints are shown in Table 6 and Figure 14. Note that the values of bending moment produced by the HEB model fall in between those calculated by the other two methods. In addition, the existing research shows that the UR model ignores the effect of joint and artificially 
TABLE 5: Summary of calculation parameters.

\begin{tabular}{|c|c|c|}
\hline Parameters & Value & Illustrate \\
\hline Vertical load, $p_{1}(\mathrm{kPa})$ & 223.32 & Whole earth-pillar load \\
\hline Horizontal load on the top of the tunnel, $q_{1}(\mathrm{kPa})$ & 111.66 & \\
\hline Horizontal load on the bottom of the tunnel, $q_{2}(\mathrm{kPa})$ & 170.16 & Lateral pressure coefficient is 0.5 \\
\hline Rock resistant coefficient, $k\left(\mathrm{MPa} \cdot \mathrm{m}^{-1}\right)$ & 100 & {$[23]$} \\
\hline Segment width, $b(\mathrm{~m})$ & 1.5 & \\
\hline Segment thickness, $h(\mathrm{~m})$ & 0.3 & \\
\hline $\begin{array}{l}\text { Thickness of the reinforcement protective layer of } \\
\text { segment, } h(\mathrm{~cm})\end{array}$ & 5.0 & / \\
\hline Elastic modulus of bolt, $E_{\mathrm{s}}(\mathrm{MPa})$ & $2.06 \times 10^{5}$ & \\
\hline Effective length of bolt, $L(\mathrm{~cm})$ & 46.0 & \\
\hline Cross-sectional area of bolt, $A_{\mathrm{g}}\left(\mathrm{mm}^{2}\right)$ & 1017.88 & Grade 8.8 M36 \\
\hline Thickness of transferring cushion, $l_{2}(\mathrm{~mm})$ & 5.0 & 1 \\
\hline $\begin{array}{l}\text { Total cross-sectional area of steel bar inner side of the } \\
\text { segment, } A_{\mathrm{s}}\left(\mathrm{mm}^{2}\right)\end{array}$ & 3770.4 & $12 Ф 20$ \\
\hline Number of circular bolt on each joint, $n$ & 2 & / \\
\hline Elastic modulus of segment concrete, $E_{\mathrm{c}}(\mathrm{MPa})$ & $34.5 \times 10^{3}$ & C50 \\
\hline Poisson's ratio of segment concrete, $\mu$ & 0.17 & C50 \\
\hline Elastic modulus of transferring cushion, $E_{\mathrm{p}}(\mathrm{MPa})$ & $0.4 \times 10^{3}$ & 1 \\
\hline $\begin{array}{l}\text { Distance from the bolt centroid to the segment inner } \\
\text { side, } h_{0}(\mathrm{~cm})\end{array}$ & 12.0 & / \\
\hline Effective length of equivalent beam element, $l(\mathrm{~m})$ & 0.1 & / \\
\hline Tensile stiffness of bolt, $K(\mathrm{~N})$ & $2.1 \times 10^{5}$ & / \\
\hline $\begin{array}{l}\text { The ratio between the cross-sectional area of bolt and } \\
\text { the cross section of steel bar inner side the segment, } \\
\alpha\end{array}$ & 0.54 & / \\
\hline $\begin{array}{l}\text { Equivalent elastic modulus of equivalent beam } \\
\text { element under axial compressive condition, } E_{\mathrm{eq}} \\
(\mathrm{MPa})\end{array}$ & $6.82 \times 10^{3}$ & / \\
\hline Initial pretightening force of bolt, $T_{0}(\mathrm{kN})$ & 200 & Grade 8.8 M36 \\
\hline
\end{tabular}

increases the stiffness of structure; thus, the calculation result of bending moment is slightly high. By contrast, the MUR model may result in lower values as expected [8]. Therefore, the HEB model can better reflect the effect of joint on the stiffness of lining structure than the other two models.

Further analysis shows that the presence of joints has the greatest impact on the distribution of bending moment. The maximum difference can be as high as $24 \%$. Its impact on axial force is relatively small, with $5 \%$ difference, which is consistent with the practical situation $[12,14,15]$.

\section{Conclusions}

Starting from-force transferring properties of segment joint, this paper converts a noncontinuous segment structure into a continuous heterogeneous structure through equivalent conversion of mechanical parameters of a joint section. The solution of equivalent mechanical parameters of joint section is deduced and obtained according to material mechanics, thus avoiding the uncertainty and complexity of segment calculation induced by joint. An iterative calculation flow of the proposed HEB model is also provided.

Model validation and applications show that the axial forces of a segment structure obtained by all models are slightly different, and all models can meet the accuracy

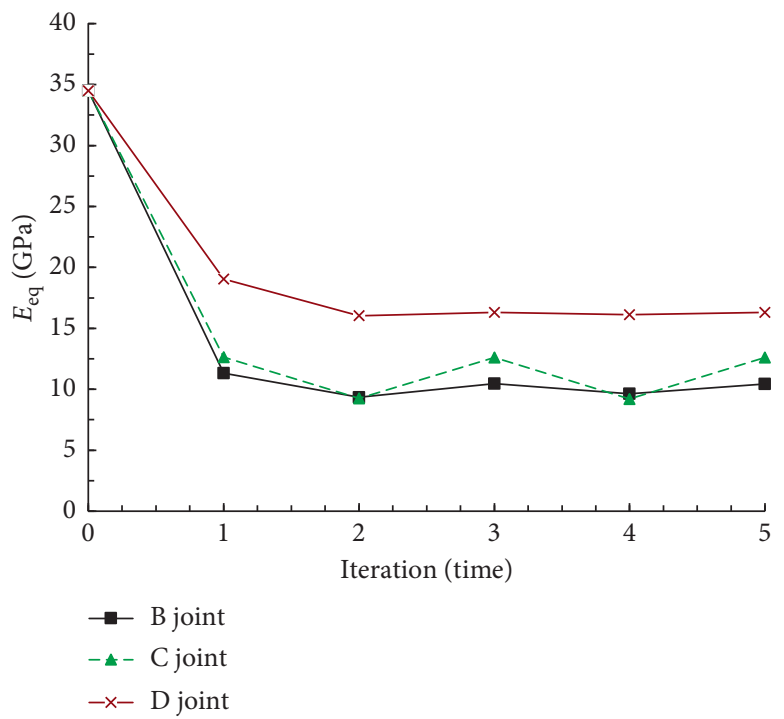

FIgURE 11: Iteration process of the equivalent elastic modulus on joint elements.

requirement of engineering application. However, for bending moment, simulation results are considerably different; particularly in the joint section, where the maximum deviation of bending moment obtained by the proposed HEB model can be up to $20 \%$ and more. 


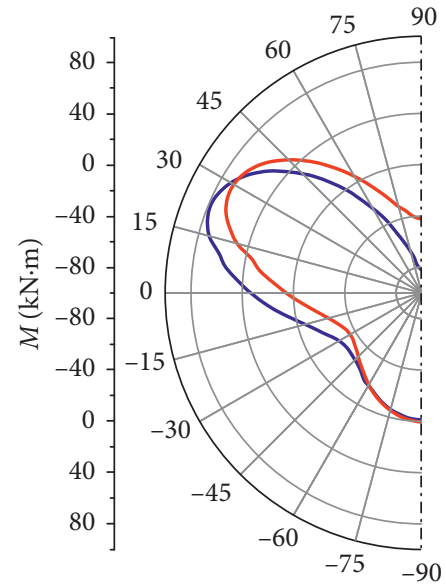

The 2nd interation

(a)

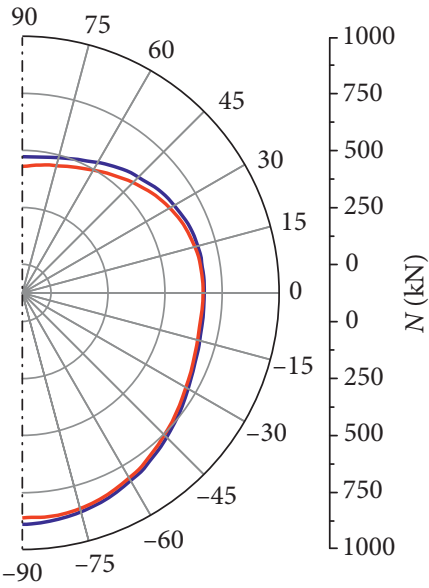

- The 2nd interation

- The 5th interation

(b)

Figure 12: Iteration results of the HEB model. (a) Bending moment. (b) Axial force.
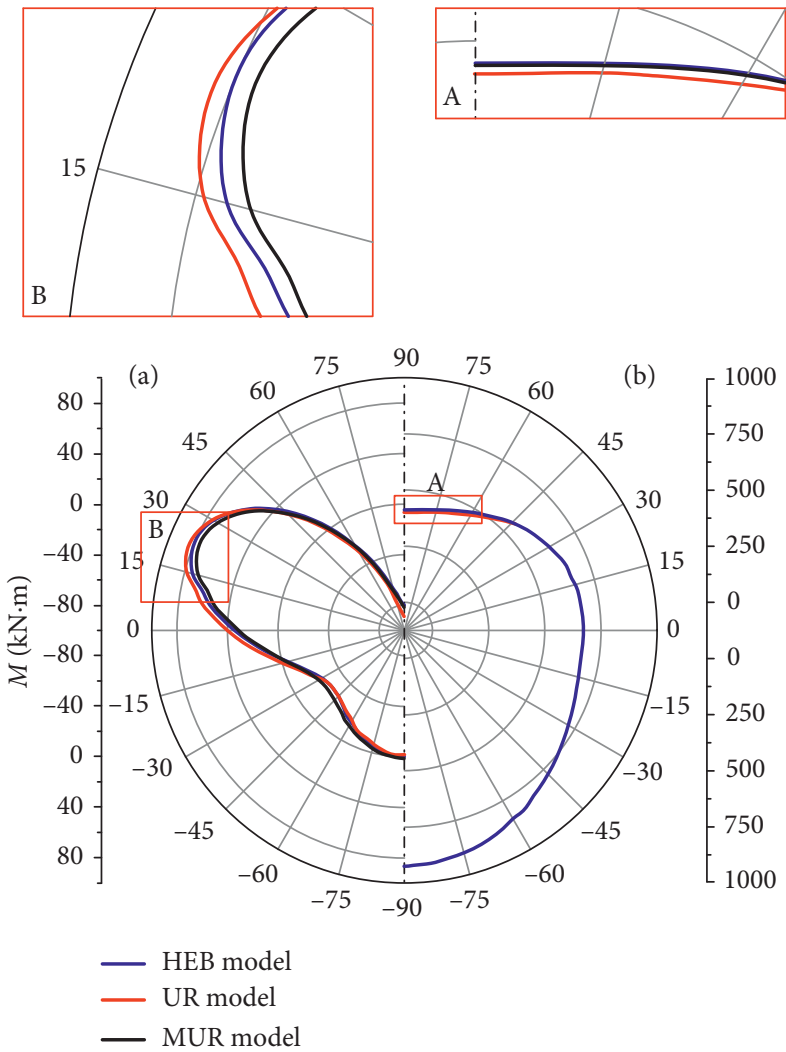

Figure 13: Calculation results by three models. (a) Bending moment. (b) Axial force.

Therefore, the selection of calculation model is very important in design analysis. Comparative analysis of different segment structure calculation models shows that the proposed heterogeneous equivalent model can better reflect the effects of joint on the stiffness of a segment. The proposed model provides reliable results with better convergence. Thus, the proposed model may provide useful suggestions for designers, engineers, and scholars who focus on the designing of shield tunnel, assessment of segment joints' stability and durability, maintenance of shield tunnel subway, and investment estimation of subway operation. 
TABLE 6: Final calculation results of inner force on joint sections calculated by the 3 models.

\begin{tabular}{lccr}
\hline Models & Joints & & Inner force \\
& & $M(\mathrm{kN} \cdot \mathrm{m})$ & $N(\mathrm{kN})$ \\
\hline \multirow{3}{*}{ UR model } & $\mathrm{B}$ & 80.03 & 477.34 \\
& $\mathrm{C}$ & 67.12 & 692.69 \\
\hline \multirow{3}{*}{ MUR model } & $\mathrm{D}$ & 19.78 & 831.50 \\
& $\mathrm{~B}$ & 72.96 & 485.87 \\
& $\mathrm{C}$ & 56.95 & 695.20 \\
HEB model & $\mathrm{D}$ & 15.95 & 838.90 \\
& $\mathrm{~B}$ & 71.79 & 484.00 \\
& $\mathrm{C}$ & 61.32 & 694.42 \\
& $\mathrm{D}$ & 19.11 & 835.54 \\
\hline
\end{tabular}

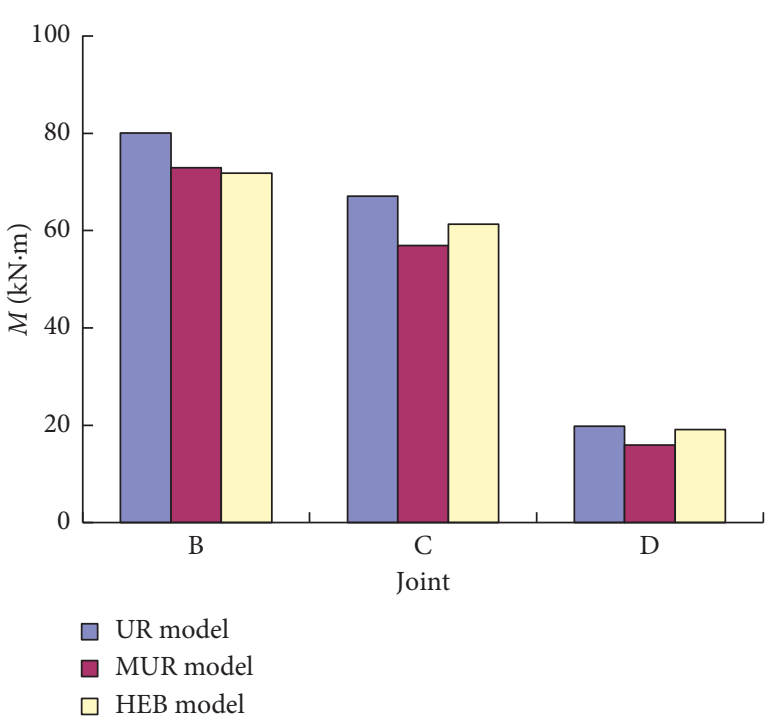

(a)

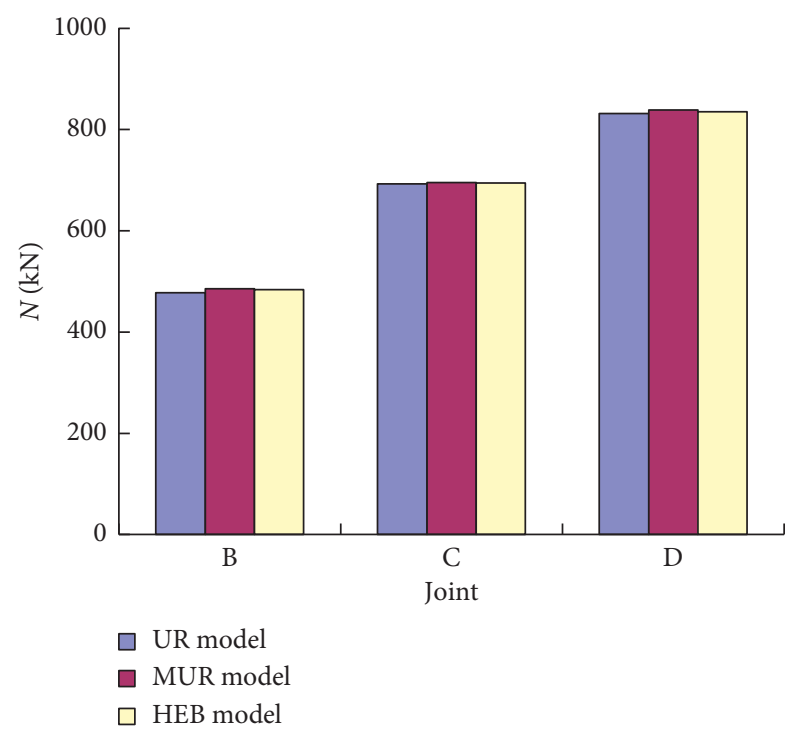

(b)

Figure 14: Comparison of inner force on joint sections. (a) Bending moment. (b) Axial force.

\section{Nomenclature}

UR model: Uniform rigidity ring model

MUR Modified uniform rigidity ring model

model:

HEB

model:

$E_{\mathrm{c}}, \mu$ :

$\sigma:$

$x$ :

$N, M:$

$\sigma_{c, \max }$

$\sigma_{\mathrm{c}, \min }:$

$h, b$ :

$n$ :
Heterogeneous equivalent beam model

Elastic modulus and Poisson's ratio of segment concrete

Stress of the edge of concrete

Effective height of compressed area of concrete of a joint section

Axial force and bending moment of a section of segment joint

Compressive stress outside and inside of joint section

Thickness and width of segment

Number of bolts in the calculation width of segment
$T_{\mathrm{b}}, T_{0}$ : Pulling force and initial pretightening force of single bolt

$h_{0}$ : $\quad$ Distance from the centroid of bolt to the inside edge of segment

$\varepsilon_{\mathrm{b}}: \quad \quad$ Strain at bolt in joint section

$\varepsilon_{c, \text { max }}$, Inside and outside edge strains of concrete of

$\varepsilon_{c, \text { min }}: \quad$ joint section

$E_{\mathrm{eq}}$ : $\quad$ Equivalent compressive elastic modulus of joint beam element

$A, l$ : Cross-sectional area and effective length of equivalent beam element

$l_{1}$ : $\quad$ Length of concrete in the range of joint beam element

$l_{2}, E_{\mathrm{p}}$ : Thickness and elastic modulus of sealing rubber strip and transferring cushion

$K, E_{\mathrm{s}}, A_{\mathrm{s}}$ : Tensile stiffness, elastic modulus, and cross-sectional area of bolt

$N^{\prime}, M^{\prime}$ : Axial force and bending moment of the section of an equivalent beam element 


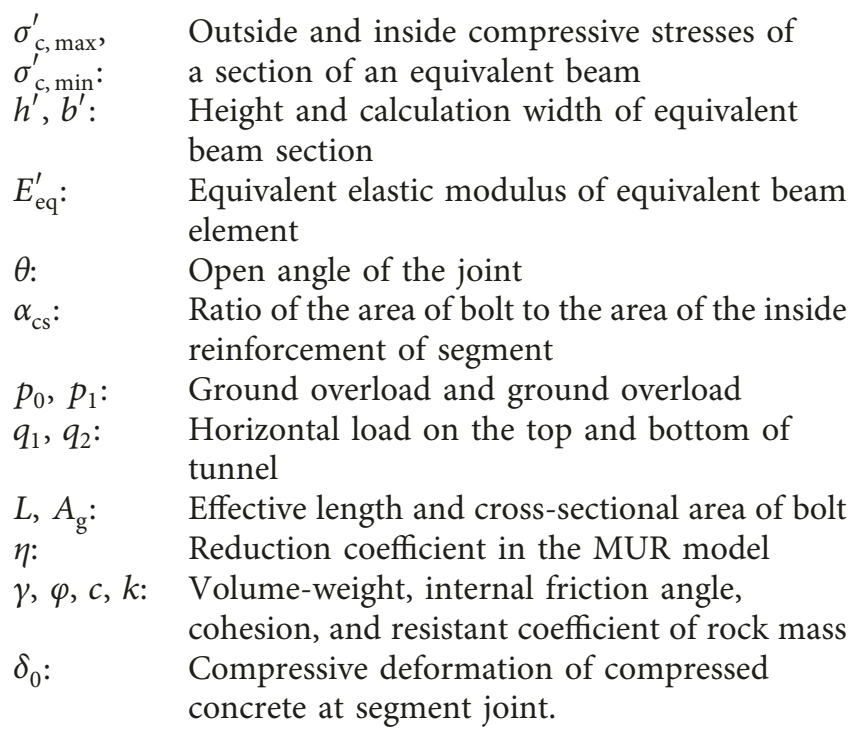

\section{Data Availability}

The data used to support the findings of this study are available from the corresponding author upon request.

\section{Conflicts of Interest}

The authors declare that they have no conflicts of interest.

\section{Acknowledgments}

Projects funded by the National Natural Science Foundation of China (nos. 51508575 and 51808416), the National Basic Research Program of China (no. 2011CB013802), the China Postdoctoral Science Foundation (nos. 2014M560652 and 2016T90764), the Innovative Talents of Science and Technology Plan of Hunan Province (no. 2015RS4006), and the Provincial Commonweal Science Foundation of Zhejiang (PCSFZ, no. 2017C33220) are gratefully acknowledged.

\section{References}

[1] X. J. Li, Z. G. Yan, Z. Wang, and H. H. Zhu, "Experimental and analytical study on longitudinal joint opening of concrete segmental lining," Tunnelling and Underground Space Technology, vol. 46, pp. 52-63, 2015.

[2] M. F. Lei, L. M. Peng, and C. H. Shi, “An experimental study on durability of shield segments under load and chloride environment coupling effect," Tunnelling and Underground Space Technology, vol. 42, pp. 15-24, 2014.

[3] M. C. Zhang, "Analysis of lining segments for circular shield tunnels," Modern Tunnelling Technology, vol. 46, no. 5, pp. 23-27, 2009, in Chinese.

[4] C. Klappers, F. Grubl, and B. Ostermeier, "Structural analyses of segmental lining-coupled beam and spring analyses versus 3D-FEM calculations with shell elements," Tunnelling and Underground Space Technology, vol. 21, no. 3-4, pp. 254-255, 2006.

[5] W G N, \& Association I T, "Guidelines for the design of shield tunnel lining," Tunnelling and Underground Space Technology, vol. 15, no. 3, pp. 303-331, 2000.
[6] K. M. Lee, X. Y. Hou, X. W. Ge, and Y. Tang, "An analytical solution for a jointed shield-driven tunnel lining," International Journal for Numerical and Analytical Methods in Geomechanics, vol. 25, no. 4, pp. 365-390, 2001.

[7] Y. Koyama, "Study on the improvement of design method of segments for shield-driven tunnels," RTRI Report: Special No. 33, RTRI, Tokyo, Japan, 2000.

[8] F. Ye, C. F. Gou, H. D. Sun, Y. P. Liu, Y. X. Xia, and Z. Zhou, "Model test study on effective ratio of segment transverse bending," Tunnelling and Underground Space Technology, vol. 41, pp. 193-205, 2014.

[9] R. B. Peck, A. J. Hendron, and B. Mohraz, "State of the art of soft ground tunnelling," in Proceedings of 1st Rapid Excavation and Tunnel Conference, vol. 1, pp. 259-286, Chicago, IL, USA, 1972.

[10] A. M. Muir Wood, "The circular tunnel in elastic ground," Geotechnique, vol. 25, no. 1, pp. 115-127, 1975.

[11] Japan Society of Civil Engineers (JSCE), The Design and Construction of Underground Structures, Tokyo, Japan, 1977.

[12] Y. Koyama, "Present status and technology of shield tunnelling method in Japan," Tunnelling and Underground Space Technology, vol. 18, no. 2-3, pp. 145-159, 2003.

[13] M. F. Lei, "Research on calculation methods of life-cycle structure performance of shield tunnel in aggressive environment," Central South University, Changsha, China, 2013, in Chinese.

[14] H. H. Zhu and L. B. Tao, "Study on two beam-spring models for the numerical analysis of segments in shield tunnel," Rock and Soil Mechanics, vol. 19, no. 2, pp. 26-32, 1998, in Chinese.

[15] X. Y. Hu, Z. X. Zhang, and L. Teng, "An analytical method for internal forces in DOT shield-driven tunnel," Tunnelling and Underground Space Technology, vol. 24, no. 6, pp. 675-688, 2009.

[16] W. Zhu, Code for Tunnel (Shield Driven Tunnel) and its Explanation, China Building Industry Press, Beijing, China, 2011, in Chinese.

[17] R. Guo, C. He, Z. X. Su, and Z. Z. Peng, "Study of shearing mechanical properties of segment joints of shield tunnels," Modern Tunnelling Technology, vol. 48, no. 4, pp. 72-77, 2011, in Chinese.

[18] Z. H. Huang, "Study on loading model of joints at longitudinal seam of lining segments in shield tunnel," Underground Space, vol. 23, no. 3, pp. 296-301, 2003, in Chinese.

[19] I. Teodor, "Design considerations and testing in shield-driven tunnels," in Proceedings of Ita International Congress Towards New Worlds in Tunnelling, pp. 321-326, Balkema, Rotterdam, Netherlands, 1992.

[20] I. Teodor, "Prefabricated lining, conceptional analysis and comparative studies for optional solution," in Proceedings of Ita International Congress Tunnelling \& Ground Conditions, pp. 136A-137A, Cairo, Egipt, 1994.

[21] J. M. Huang, "The choice of calculation model on shield tunnel segment," Railway Engineering, vol. 6, pp. 29-31, 2004, in Chinese.

[22] M. F. Lei, L. M. Peng, C. H. Shi, and D. Zhao, "Calculation and analysis of limit support force of shield tunnel excavation face under facing-slope conditions," Chinese Journal of Geotechnical Engineering, vol. 32, no. 3, pp. 488-493, 2010, in Chinese.

[23] JTG D70-2004, Code for Design of Rode Tunnel, Specification, China Communications Press, Beijing, China, 2004, in Chinese. 


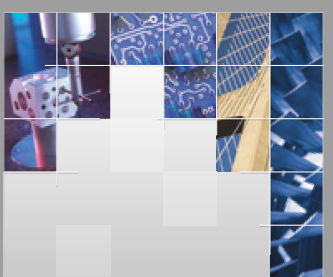

\section{Enfincering}
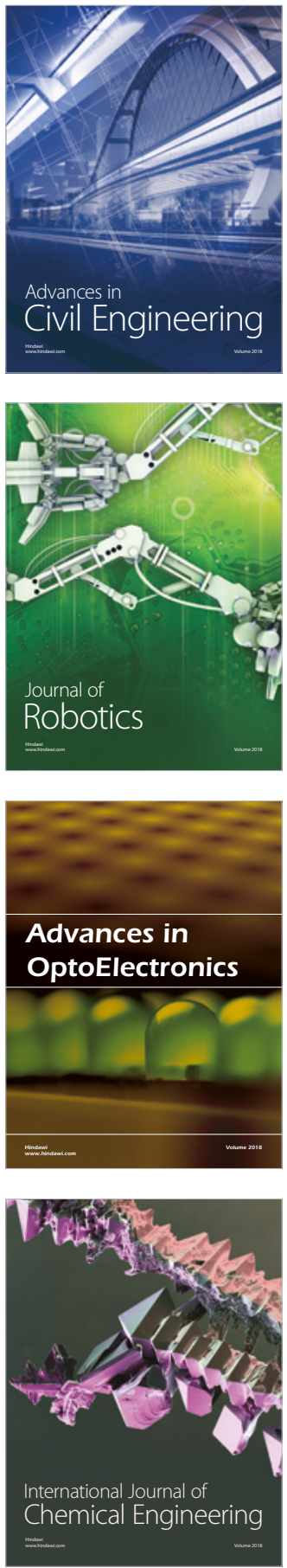

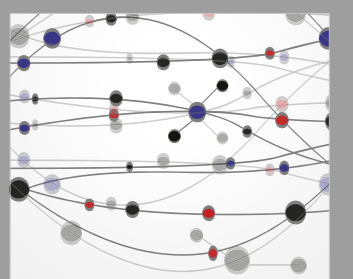

\section{Rotating \\ Machinery}

The Scientific World Journal

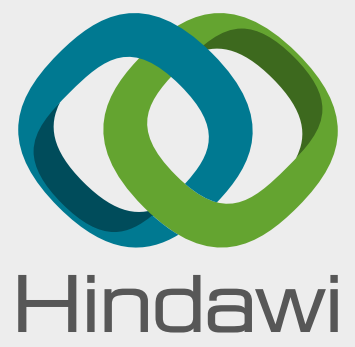

Submit your manuscripts at

www.hindawi.com
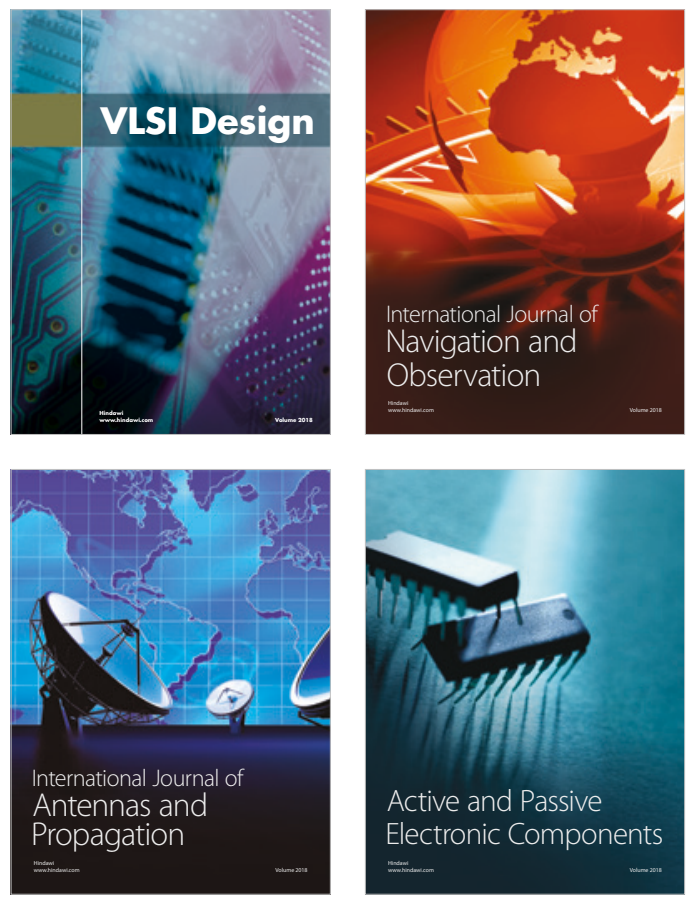
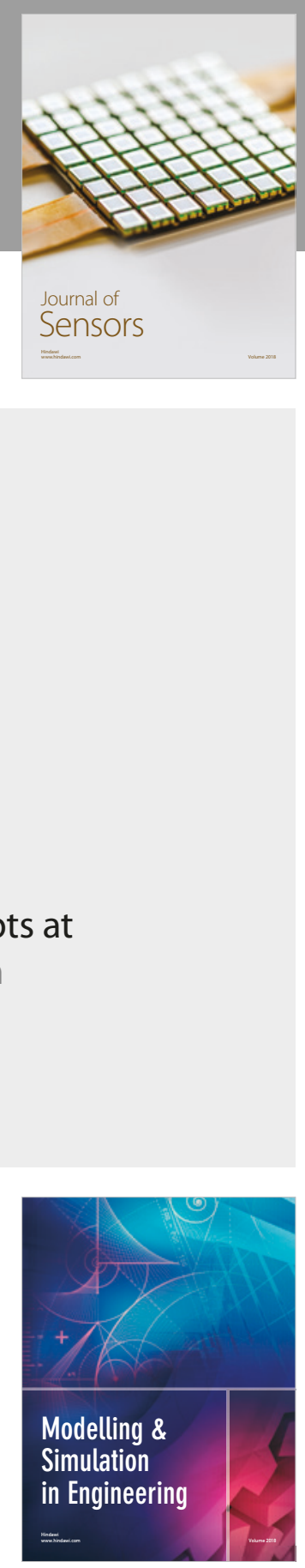

\section{Advances \\ Multimedia}
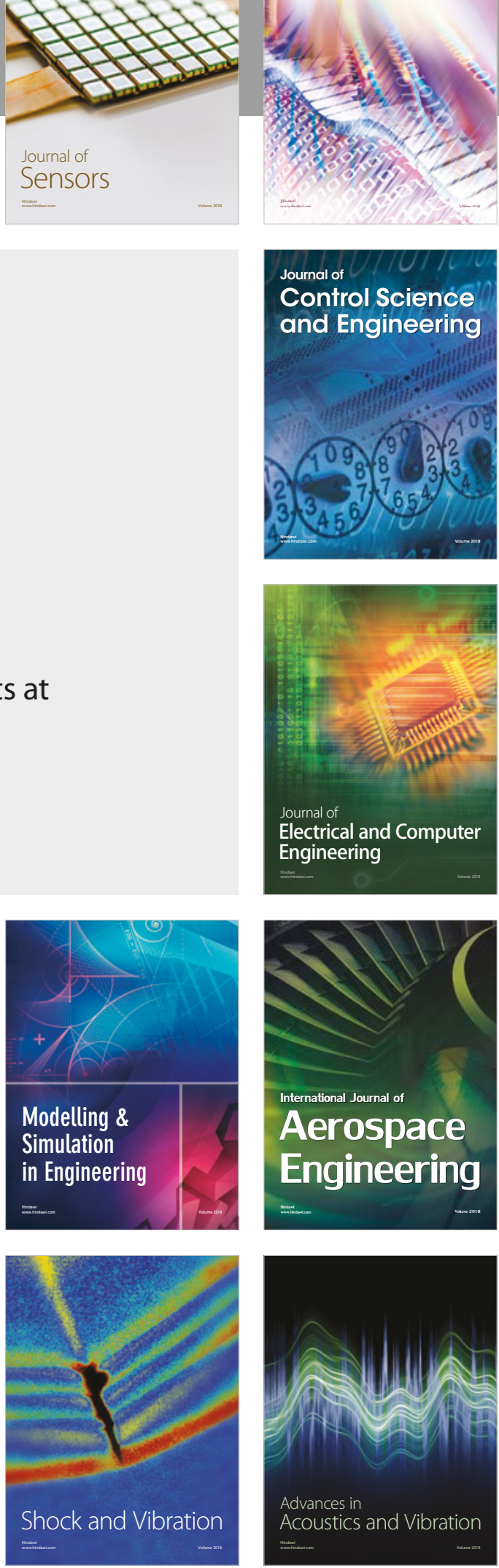